\title{
Incidence of Dirofilaria Immitis (Leidy) in Client Owned Dogs from the Greater Metropolitan Manila Area of Luzon Island in The Philippines
}

\author{
J.H. Theis ${ }^{*}, 1$, S.T. Tran ${ }^{1}$, M.P. Carlos ${ }^{2}$, E.T. Carlos ${ }^{3}$ and S.M.E. Carlos ${ }^{3}$ \\ ${ }^{I}$ Department of Medical Microbiology, School of Medicine, UC Davis, One Shields Avenue, Davis, CA 95616, USA \\ ${ }^{2}$ Division of Virology and Immunology, Public Health Laboratory, 455 First Avenue, Room 974, New York, NY 10016, \\ USA \\ ${ }^{3}$ Makati Dog and Cat Hospital, 5426 General Luna Street, Poblacion, Makati City 1210 Philippines
}

\begin{abstract}
Serum samples were collected from each of 290 healthy dogs 6 months of age or older living in the Greater Metropolitan Manila (GMM) area over a 12 month period. These samples were examined by the Synbiotics DiroChek ${ }^{\circledR}$ antigen capture test (San Diego, CA) for evidence of Dirofilaria immitis circulating antigen. At the time of the first sample 220 out of 290 examined were negative by the DiroChek test. Twelve months later 175 of the original 220 uninfected dogs were still uninfected. This is an incidence rate of $20 \%$. This is the first incidence study on client owned dogs reported for D. immitis and illustrates that owners will participate in such studies which are essential if canine populations are to be monitored to evaluate the effect of control efforts.
\end{abstract}

\section{INTRODUCTION}

Dirofilaria immitis is a mosquito vectored filarial worm that resides, as an adult, in the pulmonary arterial tree of the dog and other canids [1].

There are significant pathological effects in the lung, incident to thrombosis of branches of the pulmonary artery. Lung damage reduces the exercise tolerance and, indirectly, the cardiac function of infected animals [2-4].

The filarial worm is world wide in distribution and is capable of developing in numerous species of mosquitoes [5]. In addition in high enzootic areas the infection may spill over from canids to cats and humans [6].

There are no organized control programs for D. immitis anywhere in the World that have surveillance programs in place to measure canine incidence rates on a regular basis. The veterinary medical profession has been content to sell prophylactic drugs for the prevention of D. immitis infection but has not established a means of determining what level of prophylaxis, within a canine population, is actually necessary to reduce transmission success below replacement levels. There are no data to show whether, in any enzootic region of the world, the incidence of D. immitis is going up, staying static or declining. Such information is essential if Pet owners are to be accurately advised regarding the risk of infection to their pets and practitioners are to be in a position to recommend cost effective use of the prophylactic drugs available to prevent infection.

*Address correspondence to this author at the Department of Medical Microbiology, School of Medicine, UC Davis, One Shields Avenue, Davis, CA 95616, USA; Tel: (530) 752-3427; Fax: (530) 752, 8692;

E-mail: jhtheis@ucdavis.edu
Incidence studies using client owned dogs are difficult to conduct. In order to compensate for attrition of the subjects, for any number of reasons, a large number of dogs must be enrolled to begin with. Owners of pets are often reluctant to subject them to repeated blood sampling and in many places the owners are unable to devote the time to transport their pets to drawing stations at given times. It is not surprising therefore to find that there are no published papers that evaluate the incidence of $\mathrm{D}$. immitis infection in client owned dogs.

The veterinary medical profession does conduct regular rabies vaccination and re-vaccination campaigns that are community based and hence draw from the local, client owned, dog population. Samples for incidence studies for D. immitis could be obtained from sentinel populations by coupling vaccination programs with serum collection for incidence studies. In a study on the immunological response of client owned dogs in the Philippines to four different rabies vaccines [7] serum samples were taken four times from 290 dogs 6 months of age or older over a 12 month period. These samples were subsequently used to test for the antigen of D. immitis.

While a single incidence study is not, in and of itself, much use there is the need to establish a base line for subsequent studies in the same group of communities. Even through the results of this study are being published 15 years after the samples were drawn there has been little change in the management of the dogs in the communities surveyed in the GMM area. It also illustrates that combining vaccination programs with epizootiological surveys is acceptable to clients.

\section{MATERIALS AND METHODS}

The four serum samples were collected from each of 290 client owned dogs from ten communities in the Greater 
Metro Manila (GMM) area on the Island of Luzon, Philippines from January 1, 1991 through December 31, 1991. Luzon lies between 125 degrees and 120 degrees East Longitude at 15-18 degrees North latitude between the South China Sea and the Philippines Sea. The GMM area has a tropical climate with a 30 year mean annual rainfall of over $100 \mathrm{~cm}$. Thirty year mean annual temperature for the study area was obtained from the World Meteorological Organization [8]. From these figures the number of days required for development of third stage larvae in vector mosquitoes was calculated to be between 7.3 and 14.3 days throughout the year [9-12].

All dogs were examined for evidence of disease before blood was drawn the first time. Only dogs with no evidence of illness were enrolled in the study. Cluster sampling from ten communities in the GMM area constituted the method by which dogs were sampled. Because the diagnostic test for D. immitis is not reliable in dogs under 6 months of age only dogs 6 months of age or older at the time of first presentation were examined for D. immitis infection. At the time of the first blood sample each dog was fitted with an identifying collar and assigned a number. When the owner brought the dog for subsequent blood samples, the collar was checked for verification of the identity of the dog.

Serum was collected from the clotted blood by centrifugation, placed in a labeled vial with the dog's number and frozen at $-20^{\circ} \mathrm{C}$. The serum was sent by air express over night on dry ice and stored frozen at $-30^{\circ} \mathrm{C}$ until examined by the DiroChek ${ }^{\circledR}$ test. The dry ice kept the serum samples frozen while in transit and the samples were not thawed until used in the test.

The antigen capture test marketed by Synbiotics ${ }^{\circledR}$ (San Diego, CA) and used in this study has been evaluated for sensitivity and specificity in several studies where the results of this antigen capture test were measured against necropsy findings in the same dogs [13-15] The specificity of the test in dogs with worm burdens of more than 2 female D. immitis has been consistently high, ranging from 98 to $100 \%$ in dogs that have had proven infections by necropsy [13-15]. The sensitivity of the DiroChek ${ }^{\circledR}$ test has improved over the years from $90 \%$ in early reports [13] to $98-100 \%$ in later evaluations of improved reagents $[14,15]$. In dogs with worm burdens of 2 female D. immitis or less Courtney and Zeng 2001 [16] reported a sensitivity of $71 \%$ in 89 dogs tested with the DiroChek Elisa method. In 31 dogs with more than 2 female worms present they reported a sensitivity of $94 \%$ using the DiroChek test. The specificity in uninfected dogs was $94 \%$ in $97 \mathrm{dogs}$ tested. Although the people doing the testing were not aware of the necropsy results or the sera they were testing there were two different technicians used to conduct the microwell format tests (DiroChek; Pet Chek), and each ran only half of the total samples tested. It is possible that differences in the interpretation of border line positive samples could have occurred.

In a study by Theis et al. [17] 6,078 dogs from Washington State were examined by the DiroChek test for evidence of D. immitis infection. Six of seven hundred and eighty eight dogs in Eastern Washington that were not on prophylaxis and had no history of travel out of Washington State were found positive. All the positive dogs were in a single longitudinal band between 119 and $120^{\circ}$ west longitude that extended from Pasco to Omak. Fifty eight percent (459) of the 788 Eastern Washington dogs with no travel out of Washington State came from areas outside the 119-120 west longitude band, yet none of those dogs were antigen positive by the DiroChek test. There is no reason to believe that if the DiroChek test had a low specificity only dogs between 119 and $120^{\circ}$ west longitude would have given false positive results. In North Eastern Colorado Macy et al. [18] examined 1,012 dogs using the DiroChek test and found all but 2 negative. Those two dogs were also examined by the Knott test and found to have circulating microfilaria indentified as those of D. immitis. This Colorado population had a prevalence of $0.19 \%$, and the DiroChek test gave no false positive results.

For the purposes of calculating true prevalence the specificity of the test has been considered to be $100 \%$ and the sensitivity of the test to be $98 \%$. Calculation of true prevalence from observed prevalence was done using the method reported in Greiner and Gardner [19].

Statistical calculations were conducted using Minitab student version, Release 12 for Windows, Duxbury Press 1998, and Stat Xact-8, Cytel Software Corp. Cambridge, MA. Significance was set at the 0.05 level.

For purposes of the analysis the ten communities were divided into three segments of the GMM area running north to south and approximately parallel to each other.

The Eastern segment of the GMM is comprised of samples from dogs living in the communities of Marikina, Makati and Taguig. The central segment is comprised of samples from dogs living in the communities of Quezon City, Mandaluyong and Rizal/Angono. The western segment is composed of samples from dogs in the communities of Caloocan City, Manila, Pasay City and Las Piñas City.

\section{RESULTS}

There were 290 dogs examined, 143 males, 144 females and 3 with no gender recorded. In the Western segment of the GMM there were 76 males and 85 females, 3 no gender. Central segment 48 males, 40 females and in the Eastern segment 19 males and 19 females. There was no gender bias in the dogs examined.

There were 70 out of the 290 dogs first examined found to be infected with D. immitis: 32 males, 37 females and 1 no gender recorded. Western segment 13 males, 15 females, and 1 no gender recorded. Central segment 15 males, 13 females. Eastern segment 4 males, 9 females. A two sample Ttest and confidence interval for infected males per segment versus infected females was not significantly different $(\mathrm{P}=$ $0.69, \mathrm{DF} 3,95 \%$ CI-13.8, 10.5).

For all other segmental analyses males and females were combined. Table 1 presents the data, by geographical segment, on the prevalence and incidence of $\mathrm{D}$. immitis in the GMM. A chi square test for independence of all three segments showed that there was a significant difference in prevalence between them $(\mathrm{P}=0.012, \mathrm{DF} 2)$ omitting the Western segment from a Pearson chi square test showed that there was no significant difference in prevalence between the Central and Eastern segment. $(\mathrm{P}=0.8373, \mathrm{DF} 1)$. 
Table 1. Prevalence and Incidence Dirofilaria immitis in Dogs of the Greater Metro Manila (GMM) area Luzon, Philippines

\begin{tabular}{|c|c|c|c|c|c|c|c|}
\hline \multicolumn{3}{|c|}{ Male + Female Dogs } & \multicolumn{5}{|c|}{ Male + Female Dogs } \\
\hline $\begin{array}{l}\text { Community } \\
\text { Prevalence }\end{array}$ & $\begin{array}{l}\text { Number Infected } \\
\text { Number Examined }\end{array}$ & $\begin{array}{c}\text { True } \\
\text { Prevalence \% }\end{array}$ & $\begin{array}{l}\text { Community } \\
\text { Incidence }\end{array}$ & $\begin{array}{c}T=0 \\
\text { Uninfected }\end{array}$ & $\begin{array}{c}T=0+12 \\
\text { Uninfected }\end{array}$ & $\begin{array}{l}\text { New Infections } \\
\text { Over } 12 \text { Months Period }\end{array}$ & Incidence \% \\
\hline $\begin{array}{l}\text { Western } \\
\text { segment }\end{array}$ & $\begin{array}{c}29 \\
164\end{array}$ & 18.1 & $\begin{array}{l}\text { Western } \\
\text { segment }\end{array}$ & 135 & 108 & 27 & 20 \\
\hline $\begin{array}{c}\text { Central } \\
\text { segment }\end{array}$ & $\begin{array}{l}28 \\
88\end{array}$ & 33 & $\begin{array}{c}\text { Central } \\
\text { segment }\end{array}$ & 60 & 49 & 11 & 18 \\
\hline $\begin{array}{l}\text { Eastern } \\
\text { segment }\end{array}$ & $\begin{array}{l}13 \\
38\end{array}$ & 35 & $\begin{array}{l}\text { Eastern } \\
\text { segment }\end{array}$ & 25 & 18 & 7 & 28 \\
\hline \multirow[t]{3}{*}{$\begin{array}{c}\text { Totals } \\
\text { GMM area }\end{array}$} & $\begin{array}{c}70 \\
290\end{array}$ & 24 & & 220 & 175 & 45 & 20 \\
\hline & STD 8.96 & & & & & \multicolumn{2}{|c|}{ STD 4.143} \\
\hline & $95 \%$ CI $1.07,45.60$ & & & & & \multicolumn{2}{|c|}{$95 \%$ CI $-11.29,41.29$} \\
\hline
\end{tabular}

Incidence rates between the 3 segments were not statistically different by a Cochran-Armitage trend test. Two sided test produced a $\mathrm{P}$ value of $0.6302, \mathrm{DF} 1$.

The median age of the infected and uninfected dogs examined in each of the 3 segments of the GMM was 2 years of age (Table 2). The mean age of infected and uninfected dogs showed greater variation but there was no significant difference within segments of the GMM between the age of infected and uninfected dogs (Table 2). Likewise between major segments of the GMM there was no significant difference between the age of infected and uninfected dogs $(95 \%$, $\mathrm{CI}-2.21,1.47, \mathrm{P}=0.48, \mathrm{DF} 2)$.

\section{DISCUSSION}

The sampling technique used in this study was cluster sampling in which dogs presented from ten different locations were grouped into three defined geographical area referred to as segments of the Greater Metropolitan Manila
(GMM) area. These dogs were examined for evidence of infection with D. immitis. All of the dogs examined were asymptomatic for respiratory or cardiac disease as determined by physical examination prior to the drawing of the first blood sample. All dogs were maintained out of doors, none had a history of travel out of the segment of the GMM area they lived in according to their owners. None were receiving prophylaxis for D. immitis. The dogs in this sample represented the lower socio-economic households in the GMM area and because of their owners limited financial resources received little or no veterinary medical care. The median age of all dogs examined was 2 years (Table 2). There was no gender bias in the sample of dogs examined. The climate conditions of the GMM area are similar between segments as indicated by the consistent 30 year mean annual rainfall and temperature for the area [8]. All of the characteristics that could affect exposure risk were consistent throughout the study area and sampled dogs. Only dogs 6 months of age or older were examined for D. immitis anti-

Table 2. Median and Mean Age of Infected Dogs vs Median and Mean Age of Uninfected Dogs in the Greater Metro Manila Area 1991

\begin{tabular}{|c|c|c|c|c|c|}
\hline GMM & $\begin{array}{c}\text { Median } \\
\text { Age of } \\
\text { Infected } \\
\text { Dogs } \\
\text { (Years) }\end{array}$ & $\begin{array}{c}\text { Mean } \\
\text { Age of } \\
\text { Infected } \\
\text { Dogs } \\
\text { (Years) }\end{array}$ & $\begin{array}{c}\text { Median } \\
\text { Age of } \\
\text { Uninfected } \\
\text { Dogs } \\
\text { (Years) }\end{array}$ & $\begin{array}{c}\text { Mean } \\
\text { Age of } \\
\text { Unin- } \\
\text { fected } \\
\text { Dogs } \\
\text { (Years) }\end{array}$ & $\begin{array}{c}\text { Two Sam- } \\
\text { ple T-Test } \\
\text { and 95\% } \\
\text { Confidence } \\
\text { Interval } \\
\text { Mean Age } \\
\text { Positive } \\
\text { Dogs vs } \\
\text { Negative } \\
\text { Dogs }\end{array}$ \\
\hline $\begin{array}{l}\text { Western } \\
\text { segment }\end{array}$ & 2 & $\begin{array}{l}2.91 \\
\text { STD } \\
1.88\end{array}$ & 2 & $\begin{array}{l}2.20 \\
\text { STD } \\
2.02\end{array}$ & $\begin{array}{c}\text { CI }-1.51 \\
0.10 \\
P=0.084 \\
\text { DF } 46\end{array}$ \\
\hline $\begin{array}{l}\text { Central } \\
\text { segment }\end{array}$ & 2 & $\begin{array}{l}3.45 \\
\text { STD } \\
2.69\end{array}$ & 2 & $\begin{array}{l}2.74 \\
\text { STD } \\
2.65\end{array}$ & $\begin{array}{c}\text { CI }-1.97 \\
0.57 \\
\mathrm{P}=0.27 \\
\text { DF 55 }\end{array}$ \\
\hline $\begin{array}{l}\text { Eastern } \\
\text { segment }\end{array}$ & 2 & $\begin{array}{l}2.08 \\
\text { STD } \\
1.13\end{array}$ & 2 & $\begin{array}{l}2.39 \\
\text { STD } \\
1.72\end{array}$ & $\begin{array}{c}\text { CI }-0.74 \\
1.36 \\
P=0.55 \\
\text { DF } 28\end{array}$ \\
\hline
\end{tabular}


gen, as the test used will not detect infection in dogs younger than 6 months of age.

Based upon the prevalence of D. immitis reported in an independent study [20] in a part of the GMM area (Quezon City) where $17 \%$ of 111 dogs examined were found infected we calculated the sample size necessary to have a $95 \%$ probability that our findings would be within $\pm 5 \%$ of the true prevalence for the entire GMM area [21]. The sample size needed was 226 dogs. Our study included 290 dogs.

There are some sources of potential bias in the collection of samples in this study that should be pointed out. The samples were from a rabies vaccination study and may represent a bias towards young dogs. All of the dogs, both infected and uninfected from all 3 segments of the GMM had a median age of 2 years (Table 2 ). The mean age of dogs sampled for this study ranged from 2.09 to 3.45 years of age. While there was no statistically significant difference between the age of the dogs in any segment of the GMM surveyed there is the likelihood that older dogs were not included in proportion to their presence in the general population. This means that the prevalence data may under estimate the level of infection in the population of dogs at large. There is evidence however to suggest that the general population of dogs in the GMM is young. Quitasol et al. [22] and Tieman and Carlos [23] have both reported that the attrition rate of dogs in the GMM area is around $50 \%$ per year. Since the adult D. immitis antigen, detected by the DiroChek test, is only reliably in the dogs circulation from 6 months of age onwards, due to the developmental time between L3 and adult worm only dogs 6 months of age or older could qualify for the incidence study at the initial blood draw. Out of 827 dogs vaccinated only 290 were of the minimum age and survived for the 12 month period. According to the owners about $41 \%$ of the lost dogs were slaughtered for food or sold or stolen for the same purpose during that 12 month period. The reduced life expectancy of dogs in the GMM area effectively limits the opportunity for large numbers of D. immitis infected dogs to accumulate in the population of any community.

The density of the human population in the Western segment of the GMM is greater than in the Central and Eastern segments represented in the study. This produced considerably different sample sizes. Gregory and Blackburn [20] have pointed out that irregardless of the host-parasite combination there is a bias in the way that prevalence is calculated which results in lower prevalence as the sample size increases. Given this we used an exact chi-square test for independence to evaluate the significance of the difference in prevalence between the 3 segments of the GMM. Including the Western segment in the 3 way analysis resulted in a significant difference $(P=0.012)$. This difference was due to the Western segment because an exact chi square test without the Western segment showed no significant difference in prevalence between the Central and Eastern segments of the GMM $(\mathrm{P}=0.837)$. It may well be that the true prevalence calculated for the Central and Eastern segments are too high because too small a sample was available for study. Tacal and Cooper [20] in a study done on dogs from Quezon City, one of the communities in the Central segment of the GMM found $17 \%$ of $111 \mathrm{dogs}$ sampled to be infected with D. immitis. The discrepancy between these 3 segments of the GMM in prevalence points out the inherent difficulty of us- ing prevalence figures to gain an accurate appreciation of the distribution of a parasite even in an area of uniform climate and a population of equal exposure risk.

Incidence rates for the 3 segments of the GMM were not statistically different. By a 2-sided Cochran-Armitage trend test the $\mathrm{P}$ value was 0.630. These data indicate that the transmission rate in the 3 segments of the GMM is uniform across the entire area, and averages $20 \%$ per year (Table $\mathbf{1}$ ). As noted in the introduction there are no published papers on the incidence of D. immitis in client owned dogs anywhere in the World to compare our study with. The only published study we could find on incidence rates of D. immitis infection was published by McTier et al. [25] on a group of 15 research dogs kenneled outdoors in open air in a part of Georgia and Florida, with "moderate" potential for infection with D. immitis, and a part of Louisiana with "high" potential for infection. These dogs were tested by blood examination for microfilariae and adult D. immitis antigen and found negative. They were then placed outdoors from mid April 1988 through mid April 1999, then moved indoors and held for 5 months to allow any late infections to mature to adult worms before all 15 were necropsied. The 12 month incidence rate in Louisiana was $80 \%$ (4 out of 5 infected) while those dogs in Georgia and Florida had a $100 \%$ incidence rate (10 out of 10 infected). These incidence rates are considerably higher than what we found in the GMM area and illustrate the fact that different transmission intensities are to be expected, thus necessitating that multiple sentinel populations be sampled if such variations are to be detected.

\section{ABBREVIATIONS}

\section{GMM = Greater Metropolitan Manila}

\section{REFERENCES}

[1] Kume S, Itaqaki S. On the life cycle of Dirofilaria immitis in the dog as the final host. Br Vet J 1955; 1ll: 16-24.

[2] Adcock JL. Pulmonary arterial lesions in canine Dirofilariasis. Am J Vet Res 1961; 22: 655-662.

[3] Buoro IBJ, Atwell RB. Angles at branching and the diameters of pulmonary arteries in relation to the distribution of pulmonary lesions in canine dirofilariasis. Res Vet Sci 1983; 35: 353-356.

[4] Venco L, Gencli C, Colson PV, Kramer L. Relative utility of echocardiography, radiography, serologic testing and microfilariae counts to predict adult heart worm burden in dogs naturally infected with heartworms In: Lee RF, Ward SE, Eds. Recent advances in Heartworm Disease Symposium 2001. American Heartworm Soc, Batavia, IL, 2001; pp. 111-124.

[5] Boreham PFL, Atwell RB. Ed. Dirofilariasis. Boca Raton, Florida: CRC Press 2000.

[6] Theis JH. Public health aspects of dirofilariasis in the United States. Vet Parasitol 2005; 133: 157-180.

[7] Carlos ET, Manghas LC, Batungbacal MR, et al. Comparison of Rabies Vaccines in the Field In: Dodet B and Meslin FX Eds. Third International Symposium in Rabies Control in Asia. Elsevier Press Paris; 1997; pp 1-78.

[8] World Meteorological Organization 1961-1990. Global Climate Normals. National Climate Data Center Pub. Asheville NC, Version 1.0, Edition 1998.

[9] Beam FD. Effects of Temperature on the Development of the Dog Heartworm Dirofilaria immitis in Aedes sollicitans. Proc 54th Ann Mtg N.J. Mos Exter Assoc 1967; pp 128-138.

[10] Kutz FW and Dobson RC. Effects of Temperature on the Development of Dirofilaria immitis (Leidy) in Anopheles quadrimaculatus (Say) and on Vector Mortality Resulting from this Development. Ann Ent Soc Am 1974; 67: 325-331.

[11] Christensen BM, and Hollander AL. Effects of Temperature on Vector-Parasite Relationships of Aedes trivittatus and Dirofilaria immitis. Proc Helm-Soc Wash 1978; 45: 115-119. 
[12] Hendrix CM, Schlotthauer JC, Bemrick WJ, Averbeck GA. Temperature Effects on the Development of Dirofilaria immitis in Aedes vexans In: Otto GF, Ed. Proc Heartworm Symposium 1980, Dallas, Texas. 1981; pp 9-12.

[13] Vodian MA, Bean ES, Cowan K, Palumbo N. Evaluation of a New Enzyme linked Immunosorbent Assay for the Detection of Circulating Dirofilaria immitis Antigen in the Dog. In: Otto GF, Ed. Heartworm Symposium 1986. American Heartworm Soc, Batavia, IL; 1986; pp 91-94.

[14] Courtney CH, Zeng QY, Bean ES. Sensitivity and Specificity of the DiroChek Heartworm Antigen Test for Immunodiagnosis of canine Dirofilariasis and comparison with other immunodiagnostic tests. JAAHA 1988; 24: 27-32.

[15] Hoover JP, Campbell GA, Fox JC, Claypool PL, Mullins S. Comparison of eight diagnostic blood tests for heartworm infection in dogs. Canine Practice 1996; 21: 11-19.

[16] Courtney CH, Zeng GY. Comparison of heartworm antigen test kit performance in dogs having low heartworm burden. Vet Parasitology 2001; 96: 317-322.

[17] Theis JH, Stevens F, Law M. Distribution, prevalence, and relative risk of Filariasis in dogs from the State of Washington (19971999). JAAHA 2001; 37: 339-347.

[18] Macy DW, Cheney J, Taton AG. Prevalence of circulating heartworm antigen in dogs in Northeastern Colorado. Cornell Vet 1991; 81: 379-387.
[19] Greiner M, Gardner IA. Application of diagnostic tests in veterinary epidemiologic studies. Preventive Vet Med 2000; 45: 43-59.

[20] Tacal JV. Cooper L. A Survey on the Incidence of Dirofilaria immitis Infection in Dogs on the Diliman Campus of the University of the Philippines. Thesis College of Veterinary Medicine, 1963; University of the Philippines, Diliman, Quezon City, pp 181-187.

[21] Sheafer RL, Mendenhall W, Ott L. Chapter 4 in Elementary Survey Sampling 2nd Ed. 1979. Duxbury Press, North Scituate Mass.

[22] Quitasol JF, Carlos ET, Ventura D. Jr. Rabies Eradication Program: The Siquidor Experience In: Landicho EF, Maala, CP, Mateo, AA, Villa Corte, ESV. Eds. Proceedings of the 8th Congress of Federation of Asian Veterinary Assoc Nov. 21-25, Philippines Vet Med Assoc 1992; pp. 668-682.

[23] Tieman ME, Carlos ET. Dog Population Survey in Six Barangays of Makati Metro Manila In: Proc. of 8th Congress of Federation of Asian Veterinary Association Nov. 21-25, Landicho, EF, Maala, CP, Mateo, AA, Villacote, EL Eds. Philippine Vet Med Assoc, 1992; pp. 652-667.

[24] Gregory RD, Blackburn TM. Parasite Prevalence and Host Sample Size. Parasitology Today 1991; 7: 316-318.

[25] McTier TL, McCall JW, Dzimianski MT, Raynaud JP, Holmes RA, Keister M. Epidemiology of Heartworm Infection in Beagles Naturally Exposed to Infection in Three Southern States In: Soll MD Ed. Pro. Heartworm Symposium 1992. Am Heartworm Soc Batavia IL; 1992; pp 47-57.

(C) Theis et al.; Licensee Bentham Open.

This is an open access article distributed under the terms of the Creative Commons Attribution License (http://creativecommons.org/license/by/2.5/), which permits unrestrictive use, distribution, and reproduction in any medium, provided the original work is properly cited. 